\title{
Outcome Analysis of High Tibial Osteotomy in Osteoarthritis of Knee: A Study Protocol
}

\section{Shivshankar Jadhav ${ }^{1}$, Ulhas Dudhekar ${ }^{2}$, Kiran Saoji ${ }^{3}$, S.S. Chaudhari ${ }^{4}$}

Section: Healthcare

Sci. Journal Impact

Factor: 6.1 (2018)

ICV: 90.90 (2018)

(c) (3) (8)

Copyright@IJCRR

\begin{abstract}
Junior Resident, Department of Orthopaedics, Jawaharlal Nehru Medical College, Datta Meghe Institute of Medical Sciences (Deemed University), Sawangi Meghe, Wardha, Maharashtra, India; ${ }^{2}$ Associate Professor, Department of Orthopaedics, Jawaharlal Nehru Medical College, Datta Meghe institute of Medical Sciences (Deemed University), Sawangi Meghe, Wardha, Maharashtra, lndia; ${ }^{3 P r o f e s s o r ~ a n d ~ H e a d, ~}$ Department of Orthopaedics, Jawaharlal Nehru Medical College, Datta Meghe Institute of Medical Sciences (Deemed University), Sawangi Meghe, Wardha, Maharashtra, India; ${ }^{4}$ Professor, Mechanical Engineering, Yeshwantrao Chavan College of Engineering, Nagpur, Maharashtra, India.
\end{abstract}

\section{ABSTRACT}

Background: Osteoarthritis knee is an important cause of disability in women and 8th in men. Uni-compartmental involvement of knee joint is more common in osteoarthritis leading to various deformity and pain in the knee.

Objective: To analyse the outcome based on the functional and radiological evaluation.

Methods: The study is an observational study with a prospective study design at Acharya Vinoba Bhave Rural Hospital (AVBRH) in the Orthopaedic department. Patients who are diagnosed with osteoarthritis of the knee based on X-rays will be analysed on their clinical, functional and radiological outcomes based on Oxford Knee Score and Tegner Lysholm Knee Score. The patient will be chosen based on age above 50 years and the ones who agree to participate in the study. Patients with varus deformity of more than 10 degrees and the ones with knee instability will be excluded from the study. Assessment of patient will be done based on Oxford knee scoring and Tegner Lysholm knee score The patients will be scored pre-operatively and post-operatively to evaluate the relief from pain or the symptoms before the surgery and after the surgery and scoring will be done and will be compared.

Expected Results: High tibial osteotomy is expected to help reduce the pain in osteoarthritic patients, which hampered their daily activities. This surgery will help assess the pre-operative and post-operative scores which will be assessed based on Oxford knee score and Tegmen Lysholm score.

Key Words: Osteoarthritis, High tibial osteotomy, Open wedge osteotomy, closed wedge osteotomy, varus deformity, biomechanics of the knee

\section{INTRODUCTION}

Osteoarthritis knee is $4^{\text {th }}$ most important cause of disability in women and $8^{\text {th }}$ in men. ${ }^{1}$ Knee osteoarthritis is more prevalent in India than in the west. Earlier considered a disease of elderly but in recent years it is becoming more common even in people aged less than 50 years. ${ }^{2}$ Both systemic and local risk factors appear to influence the individual joints resulting in the development of the disease. Various treatment modalities are available in the form of Uni-compartmental Knee Replacement (UKR)/Total Knee Replacement (TKR)/High Tibial Osteotomy. As the patients who have osteoarthritis belong to the rural population, performing Uni-compartmental knee replacement/total knee replacement is expensive, also a large proportion of the population is involved in farming and they want to continue their daily strenuous activities so performing Proximal High tibial osteotomy is chosen amongst such patients as it does not affect their daily routine activities. The biomechanical principle of this procedure is to redistribute the weight-bearing forces from the affected medial compartment of the knee to the lateral compartment of the knee thus helping in relieving the pain and disease progression. ${ }^{3}$

The methods of a high tibial osteotomy include i) Medial open wedge osteotomy and ii) Lateral closed wedge osteotomy of which later procedure is more common. This procedure is superior to closed wedge osteotomies as the peroneal nerve is not injured and the proximal tibiofibular joint and lateral collateral ligaments are preserved. ${ }^{4}$ Spe-

\section{Corresponding Author:}

Dr. Shivshankar Jadhav, Junior Resident, Department of Orthopaedics, Jawaharlal Nehru Medical College, Datta Meghe Institute of Medical Sciences (Deemed University), Sawangi Meghe, Wardha, Maharashtra, India; Contact: 7588226604; Email: shivshankar.jadhav007@gail.com

ISSN: 2231-2196 (Print)

Received: 25.09 .2020
ISSN: $0975-5241$ (Online)

Revised: 16.10 .2020
Accepted: 08.11 .2020
Published: 30.11 .2020 
cific etiological factors are unknown but may include mechanical overloading or extra cartilaginous factors such as synovial or vascular changes. Taking all these factors into account we perform High Tibial Osteotomy is the surgical technique for the treatment of osteoarthritis of the knee. The biomechanics of high tibial osteotomy is recalibrated the weight-bearing forces keeping in mind the anatomical and mechanical axis.

Functional outcomes were evaluated based on the treatment goals achieved. The most important goal to be achieved was the rehabilitation goal of the patient. ${ }^{5-7}$ Osteoarthritis knee is the most important cause of disability in women and $8^{\text {th }}$ in men. Uni-compartmental involvement of knee joint is more common in osteoarthritis leading to various deformity and pain in the knee. To overcome this high tibial osteotomy can be done. This helps in redistributing the biomechanics of knee by relieving the pain in osteoarthritis of the knee.

Objectives: The main objective is to analyse the outcome on basis of functional and radiological terms.

\section{MATERIALS AND METHODS}

Study design: This is a prospective study. The study will be carried out at Acharya Vinoba Bhave Rural Hospital (AVBRH) in the orthopaedic department. Patients will be diagnosed based on X-rays and clinical evaluation who will be included in the study. The follow up of these patients will be at 21 days, 42 days, 84 days and 168 days. At each followup, patients will undergo X-rays, clinical evaluation and will be evaluated on basis of Oxford knee score and Tegmen Lysholm score.

\section{Participants:}

Inclusion criteria: Adults aged 50 years and above.

\section{Exclusion criteria :}

1) Patients with flexion deformity for more than 10 degrees.

2) Patients with knee instability.

3) Patients with secondary osteoarthritis

Study size: The study size is 30 .

\section{EXPECTED RESULTS}

High tibial osteotomy is expected to help reduce the pain in osteoarthritic patients, which hampered their daily activities. This surgery will help assess the pre-operative and post-operative scores which will be assessed based on Oxford knee score and Tegmen Lysholm score.

\section{DISCUSSION}

Pain is the main indication for performing high tibial osteotomy in a patient with osteoarthritis of the knee. And the main variable where most of the gain will be expected. In this study, we will assess the patient pre-operatively and postoperatively based on the functional and radiological outcome. The patient will undergo high tibial osteotomy and the results will be calculated with the help of Oxford Knee Score and Tegner Lysholm knee score. Chiang et al. ${ }^{8}$ had used a dome-shaped high tibial osteotomy and external fixation to treat 25 knees with medial compartment arthrosis. The Knee society score in the series was outstanding at the end of 5 years in 18 knees and by the end of 15 years, it was average to good in 13 knees.

Akizuki et al. ${ }^{9}$ with 118 uni-compartmental osteoarthritides he managed them with closed high tibial osteotomy with plate fixation and followed them for 15 years it was found that $97.6 \%$ patient had fair to an excellent score. Despite excellent pain relief and enhanced function, Arthroplasty, however, would not be lifelong remedy because of the disadvantages such as being difficult and expensive and imposes functional constraints which in developing and uprising countries, it is not acceptable. ${ }^{10}$

Difficulty in revising the uni-compartmental to a total arthroplasty has always been taken into consideration. The factors affecting the results of this study most likely the valgus alignment obtained after the surgery is considered excellent. ${ }^{11}$ Some systemic conditions like hypertension, ${ }^{12}$ diabetes ${ }^{13}$ also play a key role in fracture healing and treatment of these underlying entities needs special attention. Several other related studies on bone and joint disorders are available. ${ }^{14}$

\section{CONCLUSION}

Conclusion will be drawn on completion of the study and data analysis.

Limitations: Osteoarthritis is more common in elderly aged more than 50 years mainly affecting people who perform strenuous activity mostly farmers among the rural population. So among these peoples performing the high tibial osteotomy is a good choice but as they want to perform their strenuous activity or their daily routine work, many of them deny for the operative procedure. Also, patients mostly belong to low socioeconomic status, often deny the surgery as they are not able to pay for it. For patients residing in far places, it's difficult for them to come for regular follow up. This results in improper follow-up and hamper the outcome. 


\section{ACKNOWLEDGMENT}

Authors acknowledge the immense help received from the scholars whose articles are cited and included in references to this manuscript. The authors are also grateful to authors / editors / publishers of all those articles, journals, and books from which the literature for this article has been reviewed and discussed.

Conflict of Interest: Nil

Source of Funding: Nil

\section{REFERENCES}

1. Arya RK, Jain V. Osteoarthritis of the knee joint: An overview. J Indian Acad Clin Med 2013 Apr;14(2):154-62.

2. Hui C, Salmon LJ, Kok A, Williams HA, Hockers N, van der Tempel WM, et al. Long-term survival of high tibial osteotomy for medial compartment osteoarthritis of the knee. Am J Sports Med 2011 Jan;39(1):64-70.

3. Oh CW, Park SK, Kim HJ, Kyung HS, Cho HS, Park BC, et al. Hemicallotasis for correction of varus deformity of the proximal tibia using a unilateral external fixator. J Orthop Sci 2011;16(1):44-50.

4. Keene JS, Monson DK, Roberts JM, Dyreby JR Jr. Evaluation of patients for high tibial osteotomy. Clin Orthop Relat Res 1989;243:157-65.
5. Pörn I. An equilibrium model of health. InHealth, disease, and causal explanations in medicine 1984 (pp. 3-9). Springer, Dordrecht.

6. Feinstein AR, Josephy BR, Wells CK. Scientific and clinical problems in indexes of functional disability. Annals Intern Med 1986;105(3):413-20.

7. Nordenfelt L. Towards a holistic theory of health. In On the Nature of Health 1995 (pp. 35-104). Springer, Dordrecht.

8. Chiang H, Hsu HC, Jiang CC. Dome-shaped high tibial osteotomy: a long-term follow-up study. Journal of the Formosan Medical Association. 2006 Jan 1;105(3):214-9.

9. Akizuki S, Shibakawa A, Takizawa T, Yamazaki I, Horiuchi H. The long-term outcome of high tibial osteotomy: a ten-to 20year follow-up. J Bone Joint Surg 2008;90(5):592-6.

10. Wright RJ, Sledge CB, Poss R, Ewald FC, Walsh ME, Lingard EA. Patient-reported outcome and survivorship after Kinemax total knee arthroplasty. JBJS 2004;86(11):2464-70.

11. Patond KR, Lokhande AV. Medial open wedge high tibial osteotomy in medial compartment osteoarthrosis of the knee. Nat J Med J 1993;6:105-110.

12. Higgins TF, Klatt J, Bachus KN. Biomechanical analysis of bicondylar tibial plateau fixation: how does lateral locking plate fixation compare to dual plate fixation? J Orthop Trauma 2007;21(5):301-6.

13. Gaikwad KB, Joshi NG, Selkar SP. Study of nitrosative stress in Pregnancy Induced Hypertension. J Clin Diagn Res 2017;11(3): BC06.

14. Cladius S, Jadhav U, Ghewade B, Ali S, Dhamgaye T. Study of diabetes mellitus in association with tuberculosis. J Datta Meghe Inst Med Sci Uni 2017;12(2):143. 